\title{
Assessing climate risk to support urban forests in a changing climate
}

\author{
Manuel Esperon-Rodriguez ${ }^{1}$ (1) | Paul D. Rymer ${ }^{1}$ | Sally A. Power ${ }^{1}$ | \\ David N. Barton $^{2}$ | Paloma Cariñanos ${ }^{3,4}$ | Cynnamon Dobbs ${ }^{5}$ |
}

Ana Alice Eleuterio $^{6}$ | Francisco J. Escobedo ${ }^{7}$ | Richard Hauer ${ }^{8}$ | Martin Hermy ${ }^{9}$ |

Ali Jahani $^{10}$ | Jonathan C. Onyekwelu ${ }^{11}$ | Johan Östberg ${ }^{12}$ | Diane Pataki ${ }^{13,14}$ (1) |

Thomas B. Randrup ${ }^{12}$ | Tørres Rasmussen ${ }^{15}$ | Lara A. Roman ${ }^{16}$ | Alessio Russo ${ }^{17}$ |

Charlie Shackleton $^{18}$ | Ingjerd Solfjeld ${ }^{19}$ | Natalie S. van Doorn ${ }^{20}$ |

Matthew J. Wells ${ }^{15}$ | Björn Wiström ${ }^{12}$ | Pengbo Yan ${ }^{21}$ | Jun Yang ${ }^{22,23}$ |

Mark G. Tjoelker ${ }^{1}$

${ }^{1}$ Hawkesbury Institute for the Environment, Western Sydney University, Penrith, New South Wales, Australia

${ }^{2}$ Norwegian Institute for Nature Research (NINA), Oslo, Norway

${ }^{3}$ Department of Botany, Faculty of Pharmacy University of Granada, Granada, Spain

${ }^{4}$ IISTA-CEAMA, Andalusian Institute for Earth System Research University of Granada, Granada, Spain

${ }^{5}$ Centro de Modelacion y Monitoreo de Ecosistemas, Facultad de Ciencias, Universidad Mayor, Santiago, Chile

${ }^{6}$ Instituto Latino-Americano de Economia, Sociedade e Política, Universidade Federal da Integração Latino-Americana, Foz do Iguaçu, Brazil

${ }^{7}$ Pacific Southwest Research Station, USDA Forest Service, Riverside, California, USA

${ }^{8}$ College of Natural Resources, University of Wisconsin-Stevens Point, Stevens Point, Wisconsin, USA

${ }^{9}$ Division of Forest, Nature and Landscape, University of Leuven, Leuven, Belgium

${ }^{10}$ Assessment and Environment Risks Department, Research Center of Environment and Sustainable Development and College of Environment, National Department of Environment, Tehran, Iran

${ }^{11}$ Department of Forestry and Wood Technology, Federal University of Technology, Akure, Akure, Nigeria

${ }^{12}$ Department of Landscape Architecture, Planning and Management, Swedish University of Agricultural Sciences, Uppsala, Sweden

${ }^{13}$ School of Biological Sciences, University of Utah, Salt Lake City, Utah, USA

${ }^{14}$ School of Sustainability, Arizona State University, Tempe, Arizona, USA

${ }^{15}$ Bymiljøetaten, Oslo kommune, Oslo, Norway

${ }^{16}$ Philadelphia Field Station, USDA Forest Service, Philadelphia, Pennsylvania, USA

${ }^{17}$ School of Arts, University of Gloucestershire, Francis Close Hall Campus, Cheltenham, UK

${ }^{18}$ Department of Environmental Science, Rhodes University, Makanda, South Africa

${ }^{19}$ Faculty of Landscape and Society, Norwegian University of Life Sciences (NMBU), As, Norway

${ }^{20}$ Pacific Southwest Research Station, USDA Forest Service, Albany, California, USA

${ }^{21}$ School of Tourism Management, Guilin Tourism University, Guilin, China

${ }^{22}$ Ministry of Education Key Laboratory for Earth System Modeling, Department of Earth System Science, Tsinghua University, Beijing, China

${ }^{23}$ Joint Center for Global Change Studies (JCGCS), Beijing, China 


\section{Correspondence}

Manuel Esperon-Rodriguez, Hawkesbury Institute for the Environment, Western Sydney University, Locked Bag 1797, Penrith, NSW 2751, Australia.

Email: m.esperon-rodriguez@westernsydney. edu.au

\section{Societal Impact Statement}

Globally, cities are planning for resilience through urban greening initiatives as governments understand the importance of urban forests in improving quality of life and mitigating climate change. However, the persistence of urban forests and the ecosystem benefits they provide are threatened by climate change, and systematic assessments of causes of tree dieback and mortality in urban environments are rare. Long-term monitoring studies and adaptive management are needed to identify and prevent climate change-driven failures and mortality. Research and monitoring when coupled with systematic forecasting will enable governments to incorporate climate change resilience into urban forestry planning. Future scenarios in which urban forests are resilient or in decline will depend on the management and planning actions we make today.

\section{Summary}

The management of urban forests is a key element of resilience planning in cities across the globe. Urban forests provide ecosystem services as well as other naturebased solutions to 4.2 billion people living in cities. However, to continue to do so effectively, urban forests need to be able to thrive in an increasingly changing climate. Trees in cities are vulnerable to extreme heat and drought events, which are predicted to increase in frequency and severity under climate change. Knowledge of species' vulnerability to climate change, therefore, is crucial to ensure provision of desired ecosystem benefits, improve species selection, maintain tree growth and reduce tree mortality, dieback and stress in urban forests. Yet, systematic assessments of causes of tree dieback and mortality in urban environments are rare. We reviewed the state of knowledge of tree mortality in urban forests globally, finding very few frameworks that enable detection of climate change impacts on urban forests and no long-term studies assessing climate change as a direct driver of urban tree dieback and mortality. The effects of climate change on urban forests remain poorly understood and quantified, constraining the ability of governments to incorporate climate change resilience into urban forestry planning.

A nivel mundial, las ciudades están expandiendo las áreas verdes a medida que los gobiernos comprenden la importancia de los bosques urbanos para mitigar el cambio climático y mejorar la calidad de vida de los ciudadanos. Sin embargo, la supervivencia de los bosques urbanos y los servicios ecosistémicos que brindan se ven amenazados por el cambio climático y actualmente, son muy raros los estudios sistemáticos sobre las causas de la muerte de los árboles urbanos. Se necesitan estudios de monitoreo a largo plazo y de gestión adaptativa para identificar y prevenir la mortalidad en bosques urbanos provocada por el cambio climático. Dicha investigación y monitoreo, combinados con predicciones de clima, permitirán a los gobiernos mitigar los efectos adversos del cambio climático a través de la planificación forestal urbana. Los escenarios futuros en los que los bosques urbanos sean resilientes o estén en declive dependerán de las acciones de gestión y planificación que realicemos hoy.

\section{KEYWORDS}

tree failure, tree mortality, urban planning, urban sustainability, urban trees 


\section{1 | INTRODUCTION}

More than 4.2 billion people live in urban areas, which represent $\sim 3 \%$ of the Earth's land area (Liu et al., 2014), and by 2050, it is predicted this number will increase to 6.6 billion people $(\sim 70 \%$ of the predicted global population) (UN, 2018). Within cities, urban forests comprise trees, shrubs and associated vegetation, soils and fauna in a variety of settings including streets, residential and park trees, woodlands and green belt vegetation (Miller et al., 2015). Urban forests provide numerous ecosystem services and benefits, such as heat mitigation, reduced stormwater runoff, biodiversity conservation and improvement of human health (Keeler et al., 2019), as well as other nature-based solutions, such as green roofs and walls to reduce temperature and increase energy savings (Alexandri \& Jones, 2008). Urban forests, in both public and private spaces, can also help to mitigate the adverse impacts of global climate change by absorbing greenhouse gases and storing carbon (Bastin et al., 2019; Cimburova \& Pont, 2021). Both heat mitigation and carbon storage in urban forests can contribute to meeting the target of limiting the rise in global temperature to $1.5^{\circ} \mathrm{C}$ above preindustrial levels (IPCC, 2018). However, to ensure the provision of these services as well as other nature-based solutions, cities require healthy, functioning urban forests.
Climate change-that is, any change in climate over time, whether due to natural variability or as a result of human activity (IPCC, 2014)-is a potential stressor affecting the performance and persistence of urban forests (Brandt et al., 2016; Esperon-Rodriguez, Baumgartner, et al., 2021; Ordóñez \& Duinker, 2014). A global assessment showed that more than $50 \%$ of all plant species present in urban forests are exceeding their current climatic tolerance for mean annual temperature, and, by 2050 , this proportion will increase, potentially further jeopardising the performance of urban ecosystems (EsperonRodriguez, Baumgartner, et al., 2021). Climate change also increases the frequency and severity of extreme weather events, such as heatwaves, severe droughts and floods, which also threaten urban forests (Hilbert et al., 2019; Meehl \& Tebaldi, 2004; Staudhammer et al., 2011; Yan \& Yang, 2018; Zscheischler et al., 2018). These extreme events contribute to widespread dieback and increased tree mortality (Escobedo et al., 2016; Roman et al., 2014; Smith et al., 2019) (Figure 1). Therefore, it is reasonable to assume that ongoing anthropogenic climate change will play a key role in determining species' survival and the future composition of urban forests.

Management activities, such as providing supplemental irrigation, may mitigate some of the negative effects of climate stress (Van der Veken et al., 2008). Urban forests, however, are complex

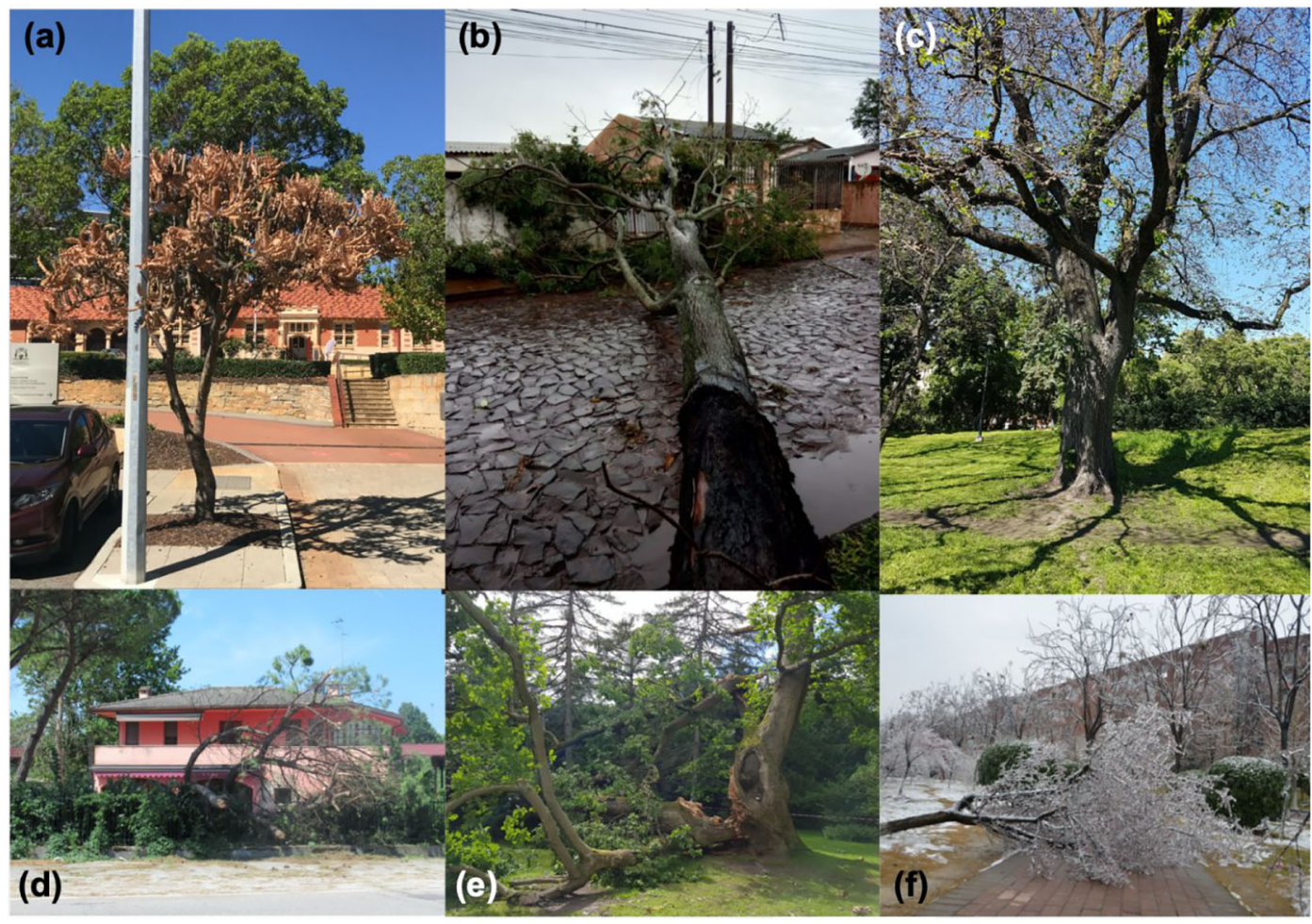

FIGURE 1 Examples of urban tree dieback and mortality as a result of extreme weather events across the globe: (a) Banksia spp. dieback after an extreme heatwave and drought event in Perth, Australia; (b) tree uprooted by a wind storm in Foz do Iguaçu, Brazil; (c) Ulmus spp. affected by a long drought period in Oslo, Norway; (d) tree damage associated with a cyclone in Padua, Italy; (e) storm damage to an oak tree in Alnarp, Sweden; and ( $f$ ) tree collapse resulting from ice formation in the tree canopy in Nanchang, China. Photos provided by the authors in order MER, AAE, IS, AR, JÖ and JY 
ecosystems, which not only experience extreme weather events, but some also face harsh conditions, such as growing in situations with limited soil volume and nutrients, soil compaction and extremes of soil moisture availability, as well as exposure to deicing salt in cold climates, which can cause severe damage and reduced vitality of urban trees (Day \& Bassuk, 1994; Gregory et al., 2006; Mullaney et al., 2015). Therefore, determining the direct drivers of urban tree dieback and mortality is challenging but essential in urban forestry planning to reduce environmental and socio-economic losses associated with failures and mortality and to ensure sustained provision of ecosystem services by urban forests (Cimburova \& Pont, 2021).

In general, tree dieback and mortality often result from a slow accumulation of the effects of many stresses through time and interactions among multiple factors (Czaja et al., 2020; Franklin et al., 1987; Hauer, Hanou, \& Sivyer, 2020; Hauer, Koeser, et al., 2020; Hilbert et al., 2019). Management decisions along the way can either exacerbate or ameliorate risks associated with tree dieback and mortality (Figure 2). Both human activities (i.e. management) and biophysical factors can be contributing causes of mortality (Hilbert et al., 2019). Inadequate management may include unsuitable plant or site selection, poor quality of nursery planting stock, inappropriate planting technique, insufficient site preparation and maintenance during the establishment period, construction (e.g. new development and redevelopment) and vandalism (Hauer, Hanou, \& Sivyer, 2020; Hauer, Koeser, et al., 2020; Hilbert et al., 2019; van Doorn \& McPherson, 2018). Biophysical factors include climate, extreme weather events, pests and diseases, herbivory and browsing (Hauer, Hanou, \& Sivyer, 2020;
Hauer, Koeser, et al., 2020; Hilbert et al., 2019). Ultimately, management and biophysical factors are strongly interrelated because management actions often involve alteration of biophysical factors, such as soil structure and water and nutrient availability (Hilbert et al., 2019).

Systematic assessments of the proximate causes of tree dieback and mortality in urban environments are rare, especially those assessing climate change as a direct driver of urban tree mortality. Therefore, the aims of this study were to (1) highlight the importance of climate change as a driver of tree dieback and mortality; (2) review the state of knowledge of urban tree dieback and mortality in urban forests globally, targeting studies reporting climate change drivers; and (3) propose recommendations to identify climate change-driven failures and prevent urban tree mortality.

\section{CLIMATE CHANGE AS A DRIVER OF URBAN TREE MORTALITY}

Urban forests are vulnerable to changes in climate and extreme weather events, with some species being more vulnerable than others. Thus, incorporating the role of climate change as a driver of urban tree dieback and mortality into adaptive management practices can help policymakers and urban forest managers reduce risks and economic losses. However, to date, this topic remains understudied.

Urban forests are affected by gradual or ongoing events, such as changes in climate parameters (e.g. rising temperatures and changing precipitation patterns), and by pulse or rapid one-off events

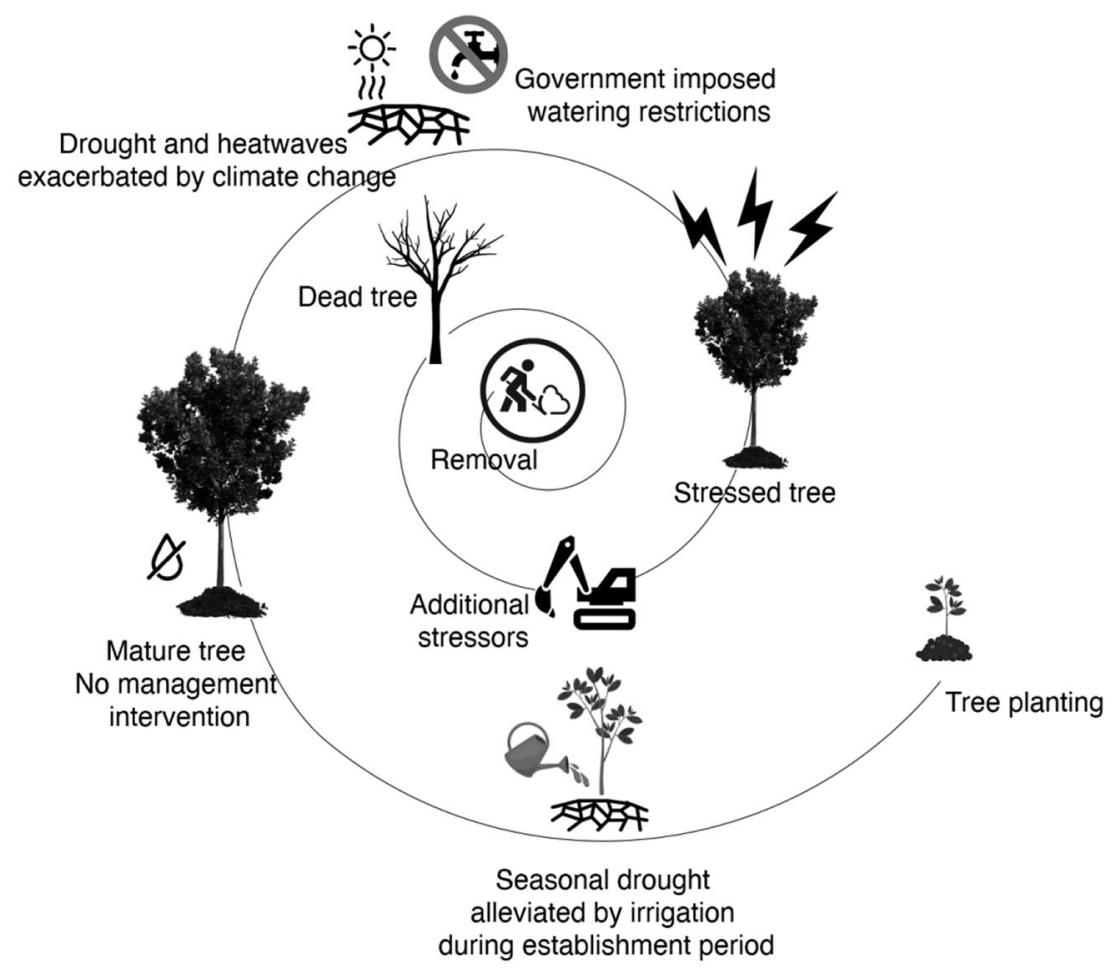

FIGURE 2 A conceptual example of the tree mortality spiral of urban tree failure and associated biophysical factors and management (adapted from Franklin et al., 1987; Hilbert et al., 2019; Manion, 1981) 
(e.g. storms). Gradual events are less studied, and research on climate change-driven mortality-that is, long-term climate change impacts on urban tree inventory dynamics-is rare. In contrast, pulse events seem easier to research-measure before and immediately after, allowing attribution of response to the specific event. In some cases, extreme weather events can be recognised as drivers of mortality. A review of 120 cities in China, for example, associated extreme temperatures and storms with increased tree mortality (Yan \& Yang, 2018). Similarly, in Sweden and Norway, extreme weather events, such as low temperature extremes and heavy snow, have been identified as causes of tree mortality (e.g. Pedersen \& Brun, 2013; Sjöman \& Slagstedt, 2015). Indeed, mortality may be linked to weather conditions during or after planting, but because planting failures may occur frequently, they are not necessarily attributed to climate events or climate change. Furthermore, these studies lacked the long-term data required to detect or attribute responses to climate change. In contrast, a study in Santiago, Chile, distinguished some effects of climate and management on tree mortality using data over a 12-year-period (2002-2014) and concluded that tree mortality was more influenced by improper management (i.e. poor species and site choice) than climate alone (Escobedo et al., 2016).

To date, however, there is a paucity of long-term monitoring studies in urban forests (see details about our literature search in Methods S1). We highlight this gap in knowledge and argue that effective urban forestry is only possible by including climate change in all its guises (e.g. extreme weather events, shifts in precipitation and temperature patterns) as a potential driver of tree mortality, crown dieback, visible injury, defoliation and poor growth, as well as secondary impacts from climate change-induced increases in pests and diseases (Linnakoski et al., 2019). As climate changes, it will become difficult to mitigate the effects of excessive heat or drought through management actions such as irrigation, to offset soil water deficits, particularly in regions with limited urban water supply (Pataki et al., 2013; Roman et al., 2014). Furthermore, there are few costeffective management options available for mitigating rising air temperature effects on trees. The long-term sustainability of urban forests, therefore, depends on the identification of species and cultivars that will continue to be suitable in a given location under climate change (McPherson et al., 2018).

Identifying species and genotypes likely to be tolerant of future climates is an option for expanding the current palette of tree species within different locales (e.g. Brandt et al., 2017; Burley et al., 2019; Esperon-Rodriguez et al., 2019; McPherson et al., 2018; Sadeghabadi et al., 2020; Steenberg et al., 2017; Yang, 2009). Initiatives such as Citree database (Vogt et al., 2017) in Germany, the Vermont Tree Selection tool (https:// vtcommunityforestry.org/resources/tree-care/tree-selection) in the United States, the Tree Species Selection Guide (Hirons \& Sjöman, 2019) for the British Isles and the Which Plant Where programme (www.whichplantwhere.com.au) in Australia provide science-based evidence on species' tolerance to inform species selection. In Iran, a recently developed tree failure model (TFM mlp tool) provides an environmental decision support system using artificial intelligence to identify trees at risk of extreme weather (e.g. wind storm) in forests (Jahani \& Saffariha, 2021). Published studies also provide valuable information on species' tolerance and climatic limits in urban settings (e.g. Brune, 2016; Burley et al., 2019; Esperon-Rodriguez et al., 2019; Esperon-Rodriguez, Baumgartner, et al., 2021; McBride \& Laćan, 2018; Smith et al., 2019; Yang, 2009). Such studies provide details on species' climatic thresholds based on their known distributions (i.e. realised climatic niches). Metrics of tree species' climate envelopes (e.g. growing degree days) or tolerance of cold (e.g. hardiness zones) can be used to inform species selection in a changing climate. For these metrics to be useful, however, they must be available to policymakers, governments and nursery growers to make informed decisions in relation to future climate.

To date, nursery growers mainly base species decisions on field trials to assign cultivars to particular hardiness zones or classes, but this approach is based on past and current climate and does not account for future climate change. Additionally, growers need research on species' climatic tolerances to inform species choice and educate consumers. Thus, rapid climate change may result in time lags between the identification and production of suitable species in nurseries, changing local climatic conditions at planting and climatic conditions over the lifespan of an individual tree. Given the comparatively slow growth rates of trees and the importance of promoting tree longevity, new species selections must be planned years or even decades in advance.

Information and knowledge on climate-sensitive species are embedded in the practice of arboriculture and urban forestry but are often not clearly collated or accessible. Where available, reports in the grey literature are often anecdotal, restricted in scale and frequently limited in scope in terms of numbers of species or sites, constraining their usefulness or broad applicability. For many cities around the globe, local governments (e.g. councils and municipalities) do not keep tree inventories, let alone accurately or consistently record mortality rates of new tree plantings or established trees (van Doorn et al., 2020). Dynamic tree inventories are costly, and thus, financial limitations make monitoring and collecting data extremely challenging and may perpetuate the lack of information (Ramage et al., 2013; Roman et al., 2013). Remote sensing data with individual tree canopy resolution do, however, offer a cost-effective approach to account for long-term changes in urban tree canopy cover (Hanssen et al., 2021), even though information on individual tree species performance may be missing.

\section{3 | RECOMMENDATIONS TO IDENTIFY CLIMATE CHANGE-DRIVEN FAILURES AND PREVENT URBAN TREE MORTALITY}

Here, we identify the information and tools needed to detect and attribute climate change as a direct driver of tree dieback and mortality in urban forests. We found two key components missing in the 
literature: (1) long-term monitoring studies assessing urban tree mortality caused by changes in climate and (2) studies on urban tree mortality caused by extreme weather events linked to climate change. Further, there is a need to incorporate climate change as a potential driver of mortality in urban tree inventories via long-term monitoring assessments. These needs arise for three main reasons. First, researchers and resource managers have yet to undertake sufficient studies of the role of climate change as a driver of tree mortality in urban forests. Second, the climate change signal, when present, can be overwhelmed by the noise of other mortality drivers. Finally, acute climate change impacts are dispersed in space and time, complicating attribution of antecedent climate events to observed urban tree mortality.

\subsection{The role of climate change as a driver of tree mortality in urban forests}

To disentangle the effects of climate change on urban forests, we recommend conducting long-term monitoring of urban forests that incorporates detailed data on growth and mortality into urban tree inventories. Also, taking a demography approach (van Doorn \& McPherson, 2018), which would entail growth, removals (incorporates mortality but recognises that sometimes trees are cut down when still alive) and plantings or recruitment. Importantly, these data will aid in identifying successes and failures of plantings within urban settings and help develop adaptive tree management plans for climate resilience (Venter et al., 2020).

We emphasise the need of implementing easy, systematic and long-term methods for collecting urban tree inventory data that document potential causes of mortality and identify risks associated with every stage of urban tree growth and development (Hauer, Hanou, \& Sivyer, 2020; Hauer, Koeser, et al., 2020; Roman et al., 2020; van Doorn et al., 2020). Tree mortality can be used as a metric to evaluate the success of planting programmes (Roman et al., 2013). Systematic data collection and monitoring should be longitudinal, tracking individual trees over time in surveys undertaken annually or every 2 years (during the establishment period, e.g. $<2$ years) or every 5 years (for established, mature trees, e.g. $>5$ years) to assess tree growth and health and evaluate specific risks or threats such as diseases and pests. Regular data collection should include size metrics of tree height (trunk and crown) and stem diameter and tree health assessments, along with symptoms of stress (e.g. diseases, pests and heat stress assessed though leaf damage; Esperon-Rodriguez, Power, et al., 2021). This last metric is very important, as climate change can affect tree performance without killing them; these effects go largely undetected in urban tree inventories.

Measuring plant traits and attributes, such as bud burst, flowering and leaf colour, can be useful in evaluating climate-driven change in plant phenology, performance and damage. Additionally, conducting experimental trials and studies of plant functional traits can provide more detailed information about species' performance and tolerance in urban environments (Esperon-Rodriguez et al., 2020; Hirons et al., 2021). Unfortunately, the current lack of such data increases uncertainty around decision-making for future urban forests.

Establishing standardised physiological tolerance metrics (e.g. leaf turgor loss point, leaf critical temperature for photosynthesis or proline content) and developing national and international inventories and assessment protocols along with urban tree mortality and growth databases can provide the means to identify vulnerable and resilient species and relate these to particular climatic conditions over the widest possible geographic areas. Selection of resilient species, therefore, should be informed by relevant life history and physiological traits. Global and regional plant trait databases such as TRY, AusTraits for Australia and BROT 2.0 for the Mediterranean Basin (Falster et al., 2021; Kattge et al., 2020; Tavşanoğlu \& Pausas, 2018) can provide information on life history and physiological traits relevant to climatic tolerances.

Field data collection protocols and quantitative guidelines based on successful existing inventories can be used to standardise data collection (McPherson et al., 2016; Roman et al., 2020). In addition to ground-based inventories, we recommend using remote sensing of urban tree cover (Hanssen et al., 2021). Monitoring protocols should capture the role of climate change and allow for data collection at regular intervals (i.e. dynamic inventories) in relation to extreme weather events. Incorporating climate trends assessments (e.g. meteorological data of trends in mean winter low temperatures, summer high temperatures and growing season precipitation) into long-term monitoring can help to identify species' responses to altered temperature and precipitation regimes and test links between the role of climatic factors and failure rates. The US Long-Term Ecological Research Network is an example of how this type of research can be conducted to address questions on forest resilience in non-urban settings (Mirtl et al., 2018).

Monitoring also should be conducted during and after periods of acute climate stress and incorporate new plantings with regular monitoring to record change of status in terms of tree health, tree mortality or damage arising from vandalism or other factors. Data collection could also integrate tree removal and planting permits into inventories to make 'living inventories' instead of 'static inventories'.

Incorporating community monitoring can aid in capturing less severe climate impacts and information about tree dieback detected by the community that do not necessarily require tree removal. The programme 'Become a Citizen Forester' from the City of Melbourne, Australia, aims to provide tools for citizens to help create resilient, healthy and diverse urban landscapes. The web tool to visualise Melbourne's urban forest has the option to locate individual trees and send emails directing concerns or updates for each tree (melbourneurbanforestvisual.com.au). Also, California USA's 'Climate ready trees' is a multi-partner study evaluating the ability of promising but underused trees to tolerate changing climates (McPherson et al., 2018). These types of initiatives can provide insights into how the community can participate 
in identifying failures and tree mortality as well as in selecting appropriate species.

Finally, we recommend developing species-level indicators that are observable and verifiable, quantitative or qualitative, relevant to local decision-making, specific and measurable, dynamic (i.e. change over relatively short time periods) and that rely on available data (Tyler, 1996). When data on species' physiological tolerances are available, these can be used to compare vulnerability among species and identify those at most risk. We recommend using indices that reflect the species' climate safety margin. For thermal tolerance, the thermal safety margin is defined as the difference between leaf temperature and the temperature at which loss of function occurs (Sunday et al., 2014). The thermal safety margin is recognised as a good indicator of species' vulnerability to climate change and their physiological capacity to cope and thrive under critical temperatures (Clusella-Trullas et al., 2021; Gallagher et al., 2019). Species' physiological tolerances are often unknown. Thus, information from species distributions and realised climatic niche limits may be informative. In this case, a thermal (or climate) safety margin can be defined as the difference between climatic niche limits of a particular species and

\section{BOX 1}

We propose three approaches to identify potential differences in climate change vulnerability among tree species and inform urban forest analysis: (1) Climate safety margin. Using data on species' climatic tolerance, the climate safety margin (S) can be calculated. This metric indicates how much warmer (or drier), a city could become before the realised climate niche limits of its species will be exceeded (EsperonRodriguez et al., 2019; Esperon-Rodriguez, Baumgartner, et al., 2021; Gallagher et al., 2019). Climate safety margin is calculated as the difference between a species climatic limit for a given climatic variable and the climate conditions of the city in which the species is planted (Figure 3). (2) Vulnerability index. When data on species' tolerance or climate niche limits are not available, a vulnerability index may be calculated using three components: the number of individuals for a given species; growth rate for a given period; and mortality rate for that period. A species may be considered more vulnerable with a lower number of individuals, lower growth rates and high mortality rates than other species in a particular urban forest inventory. (3) Integration of climate safety margin and vulnerability index. When available, integration of species' tolerance into the vulnerability index. An example used of species climate safety margins based on climate niche limits and aggregated across tree species in an urban forest inventory is shown (Figure 4). Details of the calculation of these metrics and accompanying examples are shown in Tables S1-S3. climate of the planting site (Esperon-Rodriguez, Baumgartner, et al., 2021). Data from urban tree inventories can be used to calculate climate niche-based safety margins (Box 1 ). Given that many tree species are known to grow well outside their native geographic ranges (Kendal et al., 2018), climate sensitivity inferred solely from realised climate niche limits must be interpreted carefully and supplemented with physiological tolerance information and growth and performance observations where possible.

\section{2 | Climate change signals can be overwhelmed by other tree mortality drivers}

Determining the management and biophysical factors that mitigate tree mortality in urban forests is challenging. Nonetheless, tree mortality can be minimised by (1) selecting suitable tree species for each site using information on species' climatic niche, tolerance and site requirements; (2) selecting high-quality planting stock that is free of defects and exhibits proper growth form; (3) using best practice planting techniques, which include assessing site conditions, applying rigorous planting protocols, monitoring plantings and adapting maintenance periods to specific site-conditions and species; and (4) providing long-term maintenance and monitoring to preserve existing urban trees. To assess mortality related to climate and extreme weather, we recommend experimental plantings or field trials where different factors can be controlled (McPherson et al., 2018). Also, developing long-term quantitative monitoring programmes to conduct detailed assessments of species' growth and mortality rates, including plant health and performance after extreme weather events (e.g. heatwaves and storms). This dynamic monitoring can also be used to identify resilient and vulnerable species as well as susceptibility to pests and diseases in the context of climate change (Table 1).

\section{4 | CONCLUSIONS}

The ability to assess rates of climate change-driven mortality and decline can improve planting outcomes through the long-term survival and growth of urban forests with real environmental and socioeconomic benefits. The threat of climate change, lack of inventory data, difficulties in discerning causes of tree dieback and mortality and the need for monitoring have been established in the literature previously. Yet, we still do not currently have the necessary information on urban tree resilience in the face of future climate change or the critical long-term monitoring data needed to detect and attribute climate change as a factor contributing to tree dieback and mortality in urban forests.

Whereas urban tree inventories and improved monitoring protocols are necessary to provide the essential information to underpin successful urban forest management, inventories and monitoring alone are insufficient to secure climate-resilient urban forests. The application of predictive analysis and simulation as a basis for informing urban forest management decision-making is needed. Effective 


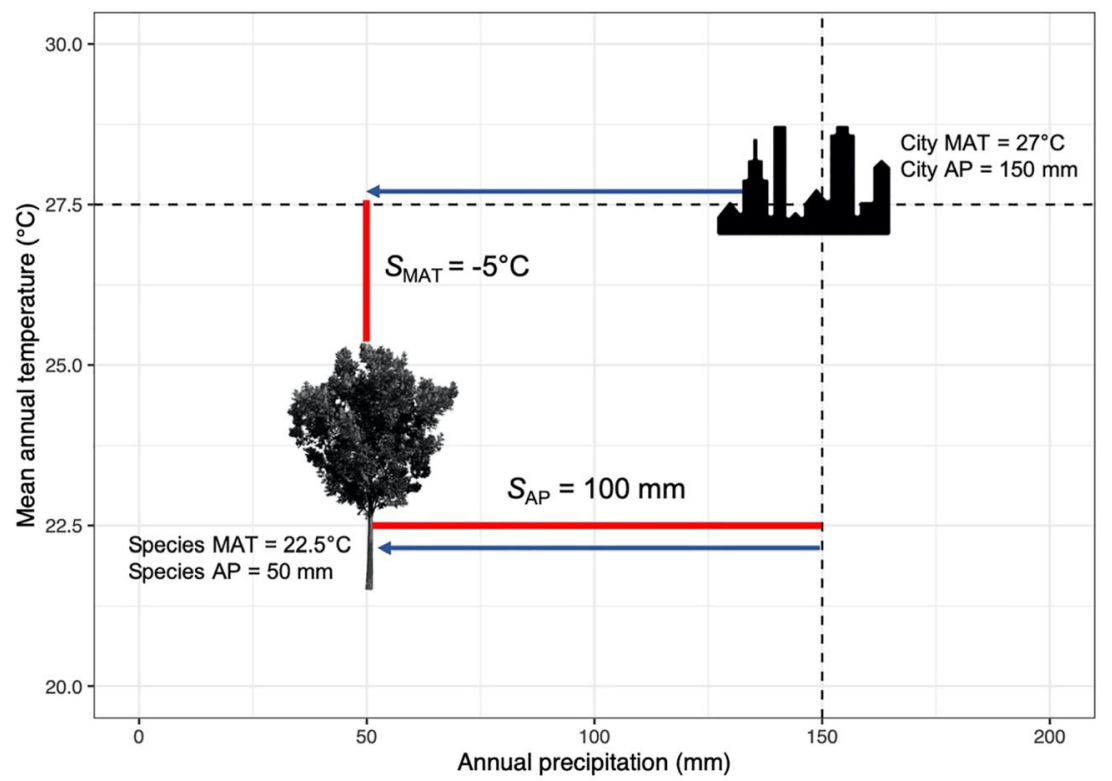

FIGURE 3 Example of the estimation of a tree species' climate safety margin for mean annual temperature $\left(S_{\text {MAT }}=S_{\text {Species climate }- \text { City }}\right.$ climate) and annual precipitation $\left(S_{\mathrm{AP}}=\right.$ City climate - Species climate) planted in a given city. For example, a tree species is planted in a city with a mean annual temperature (MAT) of $27.5^{\circ} \mathrm{C}$ and annual precipitation (AP) of $150 \mathrm{~mm}$. The species has a realised high-temperature climate limit of $22.5^{\circ} \mathrm{C}$ for MAT and a low precipitation limit of $50 \mathrm{~mm}$ for AP. Here, the planted tree species is currently experiencing unsafe conditions for MAT (i.e. Species MAT < City MAT); whereas for precipitation, the planted species is experiencing safe conditions, as the city's precipitation $(\mathrm{AP}=150 \mathrm{~mm}$ ) is much higher than the species' low precipitation limit (AP $=50 \mathrm{~mm}$ ) (i.e. Species AP < City AP). This metric can help to identify species at most risk of climate stress. Details of the calculation of these metrics are shown in Notes S1

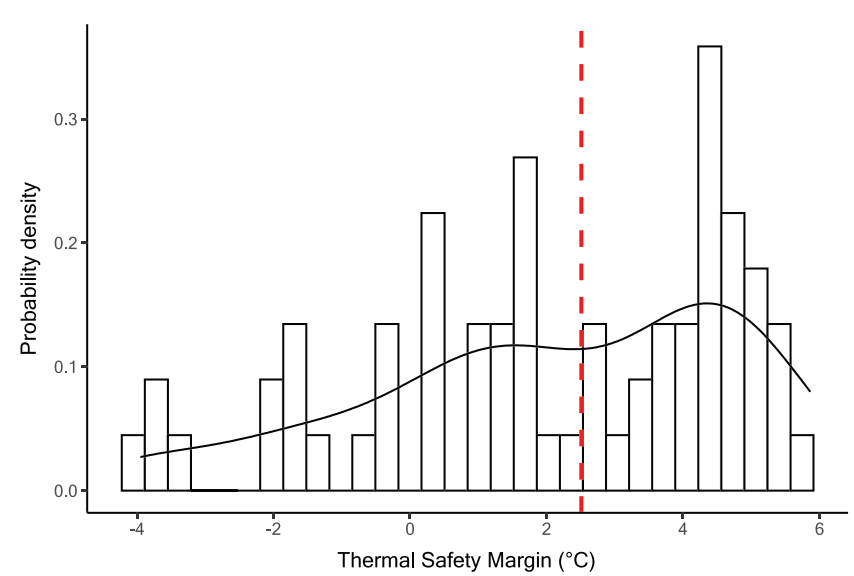

FIGURE 4 Probability density of the climate safety margin for 66 urban tree species in Sydney, Australia, using data for mean annual temperature of the species climate niche. Solid black line indicates the data distribution of individual tree species, and the red dashed line indicates the data median. Species approaching or falling below zero are considered at climate risk. Climate warming reduces the climate safety margin by shifting the axis to the right

adaptive management (e.g. Holling, 1978; Walters, 1986) will require the combination of tree inventory analysis and monitoring with forecasts of urban forest responses under different climate change and management scenarios. Currently, in urban forest planning, there is very limited use of simulation and forecasting tools to support decision-making and adaptive management over relevant decadal to century timescales. Therefore, there is a need to research and develop computational tools purpose-built for urban forestry.

To maintain sustainable urban forests in a changing climate, it will be necessary to address economic considerations to provide adequate time and effort for efficient and cost-effective establishment and maintenance of urban plantings, alongside consistent, detailed monitoring through time. We acknowledge, nevertheless, that the availability of the required information and tools will differ among locations and rely on access to financial resources. The use of big data methods based on remote sensing and integration with urban ecosystem accounting provide further options (e.g. Hanssen et al., 2021; Laumer et al., 2020).

Future research on the resilience of urban forests to climate change should incorporate multiple disciplines-including not only arborists, landscape architects and nursery owners, but other social science-based researchers and community practitioners-as central partners in the co-production of knowledge (Campbell et al., 2016). Therefore, future transdisciplinary vulnerability research and assessment of urban forest resilience to climate change will need to take into account more socio-ecological perspectives and approaches (Steenberg et al., 2017).

Determining the causes of tree mortality, or at least identifying and recording those cases in which climate might be a factor contributing to tree dieback and mortality, is fundamental for the maintenance and expansion of functional urban forests. Developing vulnerability metrics such as estimates of the climate safety margins or vulnerability indices, as proposed here, represent some examples 
TAB LE 1 Key biophysical and management factors driving urban tree failure, dieback or mortality and recommendations for mitigation

\begin{tabular}{ll}
\hline Tree failure/mortality driver & Description \\
\hline $\begin{array}{l}\text { Climate, that is, average } \\
\text { temperature and precipitation }\end{array}$ & Although human preferences influence the \\
conditions over a period & composition of urban forests (Sæbø \\
of 30 years & et al., 2003), climate remains a key factor \\
& defining species' survival and \\
& performance in cities (Kendal \\
et al., 2018)
\end{tabular}

Recommendation

Develop long-term monitoring plots stratified by different urban stressors to assess species' growth and performance. Identify the climate of origin or the climate niche of the species used for plantings to make informed decisions and decrease the probability of failure

For example, using species climate niches, a global study found that more than half of species are potentially vulnerable to climate extremes in at least one city where they are currently planted (Esperon-Rodriguez, Baumgartner, et al., 2021). Developing a species database with such species and their vulnerability at each location can be used to inform species selection (see Box 1)

Extreme weather events, which include severe or unseasonal precipitation events or drought; weather at (or beyond) the extremes of the historical climatology

Improper species selection
Extreme weather (e.g. heatwaves, flooding and storms) or drought can cause tree dieback and mortality and catalyse other factors that contribute to tree decline (Brando et al., 2014; Brandt et al., 2016; Jahani \& Saffariha, 2021)

Conduct detailed assessments of species performance and condition after extreme weather events with the aim of identifying resilient and vulnerable species. In China, over 1000 species were identified as being affected by extreme weather events (Yan \& Yang, 2018). Including such risks in a species database can help inform species selection in different locations. In Iran, hazardous trees were identified as those affected by winds exceeding $100 \mathrm{~km} / \mathrm{h}$ (Jahani \& Saffariha, 2021). Simulation models can identify the risk of tree failure in different habitats exposed to extreme storms caused by climate change

Selecting unsuitable species can decrease the success of a planting and increase the associated cost of stewardship (McPherson et al., 2018)

\section{Limited growing space}

for established trees
Inappropriate site conditions for current and future shoot and root growth increases the probability of tree failure (Hauer, Hanou, \& Sivyer, 2020; Hauer, Koeser, et al., 2020; Hilbert et al., 2020; Jahani, 2017; Jahani, 2019)

\section{Pests and diseases}

Pest and diseases may reduce tree growth and increase mortality. Climate change often increases their impact on trees (Tubby \& Webber, 2010)
Identify the site requirements and climatic tolerances of the species used for plantings to make informed decisions and decrease the probability of failure. We recommend developing a database with species' climate of origin (e.g. country, climate zone, Köppen climate classification) and site requirements (e.g. soil volume, nutrients) to improve species selection across sites

Document successes and failures to identify resilient and vulnerable species. For this, we recommend long-term monitoring of tree performance and growth using standardised metrics (McPherson et al., 2016; van Doorn et al., 2020). These data should be linked to local climatic conditions by incorporating climate information (e.g. annual precipitation, mean annual temperature, maximum temperature) into the database

Observe standard planting distances from urban structures and create proper soil rooting volume based on species' requirements before planting trees can help prevent tree failure. Develop and follow planting protocols considering species growth requirements

Assess tree growth through (1) visual inspection to detect issues, symptoms and evaluate vitality; (2) when an issue is detected, further examination is required to confirm its nature; and (3) when the defect is confirmed and may represent a risk, it should be measured, recorded and recommendations made for corresponding actions, which may include tree removal

Periodic assessment of tree health and performance, particularly in the weeks following extreme weather events such as heatwaves and drought. We suggest incorporating a health or damage score into species' databases and monitoring changes through time. Shortand long-term monitoring is crucial for these assessments 
TABLE 1 (Continued)

\begin{tabular}{|c|c|c|}
\hline Tree failure/mortality driver & Description & Recommendation \\
\hline $\begin{array}{l}\text { Poor quality of } \\
\text { nursery material }\end{array}$ & $\begin{array}{l}\text { High-quality stock is fundamental to } \\
\text { promote tree growth and establishment, } \\
\text { as poor material can harbour root and } \\
\text { shoot issues and poor root to shoot } \\
\text { balance that impair growth and survival, } \\
\text { lead to structural failure and increase } \\
\text { incidence of pathogens (Frampton } \\
\text { et al., 2002) }\end{array}$ & $\begin{array}{l}\text { Authorities and nurseries must collaborate in developing } \\
\text { and applying rigorous standards for plant material. For } \\
\text { example, the Australian national standard, AS2303 Tree } \\
\text { Stock for Landscape Use, which specifies above- and } \\
\text { below-ground criteria for assessing tree stock quality } \\
\text { (AS } 2303,2018 \text { ) } \\
\text { Develop and implement standards for tree stock quality in } \\
\text { collaboration with researchers, the nursery industry and } \\
\text { other stakeholders }\end{array}$ \\
\hline $\begin{array}{l}\text { Inappropriate establishment } \\
\text { techniques and insufficient } \\
\text { maintenance }\end{array}$ & $\begin{array}{l}\text { Disturbance from building/construction/ } \\
\text { service works that affect the root zone. } \\
\text { Tree mortality can be associated with } \\
\text { poor planting and maintenance } \\
\text { techniques and practices, which } \\
\text { exacerbate climate stresses (Breger } \\
\text { et al., 2019; Roman et al., 2013) }\end{array}$ & $\begin{array}{l}\text { Developing and applying rigorous and standardised } \\
\text { planting protocols. These protocols can be adapted } \\
\text { from existing arboriculture standards and methods } \\
\text { (Keller \& Konijnendijk, 2012; McPherson et al., 1999). } \\
\text { Protocols should be adaptable and flexible to meet } \\
\text { different goals and needs, including those of } \\
\text { practitioners, in the protocol development process as } \\
\text { well as being simple for users (Roman et al., 2013) } \\
\text { Monitoring plantings and adapting maintenance periods } \\
\text { to specific site conditions and species' responses during } \\
\text { the establishment phase. Growth data collected after } \\
\text { planting and during the establishment and post- } \\
\text { establishment phases (van Doorn \& McPherson, 2018) } \\
\text { can be used to examine growth and survivorship in } \\
\text { relation to site conditions and stewardship practices }\end{array}$ \\
\hline Poor site conditions & $\begin{array}{l}\text { Poor site conditions, such as soil } \\
\text { compaction, limited rooting volume and } \\
\text { low nutrient availability can affect } \\
\text { performance and reduce survival (Hilbert } \\
\text { et al., 2020; Trowbridge \& Bassuk, 2004) }\end{array}$ & $\begin{array}{l}\text { Prior to planting, assess soil characteristics by determining } \\
\text { pH, compaction, texture, water availability and nutrient } \\
\text { status, among others, based on regional planting } \\
\text { protocols. Sites with suboptimal conditions can be } \\
\text { improved to meet standard planting conditions by } \\
\text { identifying appropriate substrates, applying fertilisers } \\
\text { and other amendments to enhance establishment and } \\
\text { survival (Pauleit et al., 2002) }\end{array}$ \\
\hline
\end{tabular}

of new tools that can be implemented as a way forward. We call on governments, scientists and general public to work together to develop detailed long-term monitoring plans for urban forests and develop new computational tools to support adaptive management. Ultimately, the development of a knowledge base for understanding climate-driven failures requires dynamic assessments of urban forests on shorter timescales to enable policymakers and urban forest managers to better adapt and keep pace with rapid changes in climate. Given the longevity of trees in the landscape, future scenarios in which urban trees and forests are resilient or in decline will depend on the management and planning actions we make today.

\section{ACKNOWLEDGEMENTS}

We thank Leslie Brandt and Gregory McPherson (USDA Forest Service, USA), Jakub Kronenberg (University of Lodz, Poland), Shawn Landry (University of South Florida, USA) and Per Anker Pedersen (Faculty of Landscape and Society, Norwegian University of Life Sciences) for their thoughts and contributions. MER, PR, SP and MGT thank Leigh Staas (Macquarie University) and funding from the Hort Frontiers Green Cities Fund, part of the Hort Frontiers strategic partnership initiative developed by Hort Innovation, with coinvestment from Macquarie University, Western Sydney University and the NSW Department of Planning, Industry and Environment and contributions from the Australian Government. DNB acknowledges support from the Research Council of Norway to the ENABLE project through the BiodivERsA COFUND 2015-2016 call for research proposals. BW acknowledges support from FORMAS (dia.nr 2016-20098). Finally, we thank the anonymous reviewers for their critical observations and thoughtful contributions that improved this work. The opinions and findings expressed in this paper are those of the authors and should not be construed to represent any official USDA or US Government determination or policy.

\section{CONFLICT OF INTEREST}

The authors declare that they have no conflict of interest to disclose.

\section{AUTHOR CONTRIBUTIONS}

MER, PR, SP, MGT conceived the article. MER wrote the article. All authors contributed data and to the discussion of the content and reviewed or edited the manuscript before submission. Authors, excluding MER, PR, SP and MGT are listed alphabetically. 


\section{DATA AVAILABILITY STATEMENT}

The data that support the findings of this study are available in the Supporting Information of this article.

\section{ORCID}

Manuel Esperon-Rodriguez (D) https://orcid.org/0000-0003-3649-

2134

Diane Pataki (D) https://orcid.org/0000-0001-7209-514X

\section{REFERENCES}

Alexandri, E., \& Jones, P. (2008). Temperature decreases in an urban canyon due to green walls and green roofs in diverse climates. Building and Environment, 43(4), 480-493. https://doi.org/10.1016/j.buildenv. 2006.10.055

AS 2303 SA. (2018). Australian standard 2303: Tree stock for landscape use. CoSAAn. EV-018, Arboriculture.

Bastin, J.-F., Finegold, Y., Garcia, C., Mollicone, D., Rezende, M., Routh, D., Zohner, C. M., \& Crowther, T. W. (2019). The global tree restoration potential. Science, 365(6448), 76-79.

Brando, P. M., Balch, J. K., Nepstad, D. C., Morton, D. C., Putz, F. E., Coe, M. T., Silvério, D., Macedo, M. N., Davidson, E. A., \& Nóbrega, C. C. (2014). Abrupt increases in Amazonian tree mortality due to drought-fire interactions. Proceedings of the National Academy of Sciences, 111(17), 6347-6352. https://doi.org/10.1073/pnas. 1305499111

Brandt, L., Lewis, A. D., Fahey, R., Scott, L., Darling, L., \& Swanston, C. (2016). A framework for adapting urban forests to climate change. Environmental Science \& Policy, 66, 393-402. https://doi.org/10.1016/ j.envsci.2016.06.005

Brandt, L. A., Lewis, A. D., Scott, L., Darling, L., Fahey, R. T., Iverson, L., Nowak, D. J., Bodine, A. R., Bell, A., \& Still, S. (2017). Chicago wilderness region urban forest vulnerability assessment and synthesis: $A$ report from the urban forestry climate change response framework Chicago wilderness pilot project. Gen. Tech. Rep. NRS-168. Newtown Square, PA: US Department of Agriculture, Forest Service, Northern Research Station.

Breger, B. S., Eisenman, T. S., Kremer, M. E., Roman, L. A., Martin, D. G., \& Rogan, J. (2019). Urban tree survival and stewardship in a statemanaged planting initiative: A case study in Holyoke, Massachusetts. Urban Forestry \& Urban Greening, 43, 126382. https://doi.org/10. 1016/j.ufug.2019.126382

Brune, M. (2016). Urban trees under climate change. Potential impacts of dry spells and heat waves in three German regions in the 2050s. Rep. 24. Germany CSC, Hamburg.

Burley, H., Beaumont, L. J., Ossola, A., Baumgartner, J. B., Gallagher, R., Laffan, S., Esperon-Rodriguez, M., Manea, A., \& Leishman, M. R. (2019). Substantial declines in urban tree habitat predicted under climate change. Science of the Total Environment, 685, 451-462. https:// doi.org/10.1016/j.scitotenv.2019.05.287

Campbell, L. K., Svendsen, E. S., \& Roman, L. A. (2016). Knowledge coproduction at the research-practice interface: Embedded case studies from urban forestry. Environmental Management, 57(6), 1262-1280. https://doi.org/10.1007/s00267-016-0680-8

Cimburova, Z., \& Pont, M. B. (2021). Location matters. A systematic review of spatial contextual factors mediating ecosystem services of urban trees. Ecosystem Services, 50, 101296.

Clusella-Trullas, S., Garcia, R. A., Terblanche, J. S., \& Hoffmann, A. A. (2021). How useful are thermal vulnerability indices? Trends in Ecology \& Evolution, 36, 1000-1010. https://doi.org/10.1016/j.tree.2021. 07.001

Czaja, M., Kolton, A., \& Muras, P. (2020). The complex issue of urban trees-Stress factor accumulation and ecological service possibilities. Forests, 11(9), 932. https://doi.org/10.3390/f11090932
Day, S. D., \& Bassuk, N. L. (1994). A review of the effects of soil compaction and amelioration treatments on landscape trees. Journal of Arboriculture, 20(1), 9-17.

Escobedo, F., Palmas-Perez, S., Dobbs, C., Gezan, S., \& Hernandez, J. (2016). Spatio-temporal changes in structure for a Mediterranean urban forest: Santiago, Chile 2002 to 2014. Forests, 7(6), 121. https:// doi.org/10.3390/f7060121

Esperon-Rodriguez, M., Baumgartner, J., Beaumont, L., Lenoir, J., Nipperess, N., Power, S., Richard, B., Rymer, P., Tjoelker, M., \& Gallagher, R. V. (2021). Climate-change risk analysis for global urban forests. bioRxiv. https://doi.org/10.1101/2021.05.09.443030

Esperon-Rodriguez, M., Power, S., Tjoelker, M., Beaumont, L., Burley, H., Caballero-Rodriguez, D., \& Rymer, P. (2019). Assessing the vulnerability of Australia's urban forests to climate extremes. Plants, People, Planet, 1(2), 1-11.

Esperon-Rodriguez, M., Power, S., Tjoelker, M., Marchin, R., \& Rymer, P. (2021). Contrasting heat tolerance of urban trees to extreme temperatures during heatwaves. Urban Forestry \& Urban Greening, 66, 127387. https://doi.org/10.1016/j.ufug.2021.127387

Esperon-Rodriguez, M., Rymer, P. D., Power, S. A., Challis, A., Marchin, R. M., \& Tjoelker, M. G. (2020). Functional adaptations and trait plasticity of urban trees along a climatic gradient. Urban Forestry \& Urban Greening, 54, 126771. https://doi.org/10.1016/j.ufug.2020. 126771

Falster, D., Gallagher, R., Wenk, E. H., Wright, I. J., Indiarto, D., Andrew, S. C., Baxter, C., Lawson, J., Allen, S., \& Fuchs, A. (2021). AusTraits, a curated plant trait database for the Australian flora. Scientific Data, 8(1), 1-20.

Frampton, J., Isik, F., \& Goldfarb, B. (2002). Effects of nursery characteristics on field survival and growth of loblolly pine rooted cuttings. Southern Journal of Applied Forestry, 26(4), 207-213. https://doi.org/10. 1093/sjaf/26.4.207

Franklin, J. F., Shugart, H. H., \& Harmon, M. E. (1987). Tree death as an ecological process. Bioscience, 37(8), 550-556. https://doi.org/10. 2307/1310665

Gallagher, R. V., Allen, S., \& Wright, I. J. (2019). Safety margins and adaptive capacity of vegetation to climate change. Scientific Reports, 9(1), 8241. https://doi.org/10.1038/s41598-019-44483-x

Gregory, J. H., Dukes, M. D., Jones, P. H., \& Miller, G. L. (2006). Effect of urban soil compaction on infiltration rate. Journal of Soil and Water Conservation, 61(3), 117-124.

Hanssen, F., Barton, D. N., Venter, Z. S., Nowell, M. S., \& Cimburova, Z. (2021). Utilizing LiDAR data to map tree canopy for urban ecosystem extent and condition accounts in Oslo. Ecological Indicators, 130, 108007. https://doi.org/10.1016/j.ecolind.2021.108007

Hauer, R., Hanou, I., \& Sivyer, D. (2020). Planning for active management of future invasive pests affecting urban forests: The ecological and economic effects of varying Dutch elm disease management practices for street trees in Milwaukee, WI USA. Urban Ecosystem, 23(5), 10051022. https://doi.org/10.1007/s11252-020-00976-6

Hauer, R., Koeser, A., Parbs, S., Kringer, J., Krouse, R., Ottman, K., Miller, R., Sivyer, D., Timilsina, N., \& Werner, L. (2020). Effects of a tree preservation program on tree survival, condition, and growth in Milwaukee, WI, USA. Landscape \& Urban Planning, 193, 103670. https:// doi.org/10.1016/j.landurbplan.2019.103670

Hilbert, D., Roman, L., Koeser, A. K., Vogt, J., \& van Doorn, N. S. (2019). Urban tree mortality: A literature review. Arboriculture \& Urban Forestry, 45(5), 167-200.

Hilbert, D. R., North, E. A., Hauer, R. J., Koeser, A. K., McLean, D. C., Northrop, R. J., Andreu, M., \& Parbs, S. (2020). Predicting trunk flare diameter to prevent tree damage to infrastructure. Urban Forestry \& Urban Greening, 49, 126645. https://doi.org/10.1016/j.ufug.2020. 126645

Hirons, A., \& Sjöman, H. (2019). Tree species selection for green infrastructure: A guide for specifiers, issue 1.3. Group TDA. 
Hirons, A. D., Watkins, J. H. R., Baxter, T. J., Miesbauer, J. W., MaleMuñoz, A., Martin, K. W., Bassuk, N. L., \& Sjöman, H. (2021). Using botanic gardens and arboreta to help identify urban trees for the future. Plants, People, Planet, 3(2), 182-193. https://doi.org/10.1002/ ppp3.10162

Holling, C. (1978). Adaptive environmental assessment and management. Wiley.

IPCC. (2014). In C. B. Field, V. R. Barros, D. Dokken, K. Mach, M. Mastrandrea, T. Bilir, M. Chatterjee, K. Ebi, Y. Estrada, \& R. Genova (Eds.), Climate change 2014: Impacts, adaptation, and vulnerability. Part a: Global and sectoral aspects. Contribution of working group II to the fifth assessment report of the intergovernmental panel on climate change. Cambridge University Press.

IPCC. (2018). Global warming of $1.5^{\circ} \mathrm{C}$. Working Group I Technical Support Unit. Switzerland: Intergovernmental Panel on Climate Change.

Jahani, A. (2017). Sycamore failure hazard risk modeling in urban green space. Journal of Spatial Analysis Environmental Hazards, 3(4), 35-48.

Jahani, A. (2019). Sycamore failure hazard classification model (SFHCM): An environmental decision support system (EDSS) in urban green spaces. International Journal of Environmental Science and Technology, 16(2), 955-964. https://doi.org/10.1007/s13762-018-1665-3

Jahani, A., \& Saffariha, M. (2021). Modeling of trees failure under windstorm in harvested Hyrcanian forests using machine learning techniques. Scientific Reports, 11(1), 1-13.

Kattge, J., Bönisch, G., Díaz, S., Lavorel, S., Prentice, I. C., Leadley, P., Tautenhahn, S., Werner, G. D., Aakala, T., \& Abedi, M. (2020). TRY plant trait database-enhanced coverage and open access. Global Change Biology, 26(1), 119-188. https://doi.org/10.1111/gcb.14904

Keeler, B. L., Hamel, P., McPhearson, T., Hamann, M. H., Donahue, M. L., Prado, K. A. M., Arkema, K. K., Bratman, G. N., Brauman, K. A., \& Finlay, J. C. (2019). Social-ecological and technological factors moderate the value of urban nature. Nature Sustainability, 2(1), 29-38. https://doi.org/10.1038/s41893-018-0202-1

Keller, J. K.-K., \& Konijnendijk, C. C. (2012). A comparative analysis of municipal urban tree inventories of selected major cities in North America and Europe. Arboriculture and Urban Forestry, 38(1), 24-30.

Kendal, D., Dobbs, C., Gallagher, R., Beaumont, L., Baumann, J., Williams, N., \& Livesley, S. (2018). A global comparison of the climatic niches of urban and native tree populations. Global Ecology and Biogeography, 27(5), 629-637. https://doi.org/10.1111/geb.12728

Laumer, D., Lang, N., van Doorn, N., Mac Aodha, O., Perona, P., \& Wegner, J. D. (2020). Geocoding of trees from street addresses and street-level images. ISPRS Journal of Photogrammetry and Remote Sensing, 162, 125-136. https://doi.org/10.1016/j.isprsjprs.2020. 02.001

Linnakoski, R., Kasanen, R., Dounavi, A., \& Forbes, K. M. (2019). Forest health under climate change: Effects on tree resilience, and pest and pathogen dynamics. Frontiers in Plant Science, 10, 1157. https://doi. org/10.3389/fpls.2019.01157

Liu, Z., He, C., Zhou, Y., \& Wu, J. (2014). How much of the world's land has been urbanized, really? A hierarchical framework for avoiding confusion. Landscape Ecology, 29(5), 763-771. https://doi.org/10.1007/ s10980-014-0034-y

Manion, P. D. (1981). Tree disease concepts. Prentice-Hall, Inc.

McBride, J. R., \& Laćan, I. (2018). The impact of climate-change induced temperature increases on the suitability of street tree species in California (USA) cities. Urban Forestry \& Urban Greening, 34, 348-356. https://doi.org/10.1016/j.ufug.2018.07.020

McPherson, E. G., Berry, A. M., \& van Doorn, N. S. (2018). Performance testing to identify climate-ready trees. Urban Forestry \& Urban Greening, 29, 28-39. https://doi.org/10.1016/j.ufug.2017.09.003

McPherson, E. G., Simpson, J. R., Peper, P. J., \& Xiao, Q. (1999). Benefitcost analysis of Modesto's municipal urban forest. Journal of Arboriculture, 25, 235-248.
McPherson, E. G., van Doorn, N. S., \& Peper, P. J. (2016). Urban tree database and allometric equations. Gen. Tech. Rep. PSW-GTR-253. Albany, CA: US Department of Agriculture, Forest Service, Pacific Southwest Research Station.

Meehl, G. A., \& Tebaldi, C. (2004). More intense, more frequent, and longer lasting heat waves in the 21st century. Science, 305(5686), 994-997.

Miller, R. W., Hauer, R. J., \& Werner, L. P. (2015). Urban forestry: Planning and managing urban greenspaces. Waveland Press, Inc.

Mirtl, M., Borer, E., Djukic, I., Forsius, M., Haubold, H., Hugo, W. Jourdan, J., Lindenmayer, D., McDowell, W., \& Muraoka, H. (2018). Genesis, goals and achievements of long-term ecological research at the global scale: A critical review of ILTER and future directions. Science of the Total Environment, 626, 1439-1462. https://doi.org/10. 1016/j.scitotenv.2017.12.001

Mullaney, J., Lucke, T., \& Trueman, S. J. (2015). A review of benefits and challenges in growing street trees in paved urban environments. Landscape and Urban Planning, 134, 157-166. https://doi.org/10.1016/j. landurbplan.2014.10.013

Ordóñez, C., \& Duinker, P. (2014). Assessing the vulnerability of urban forests to climate change. Environmental Reviews, 22(3), 311-321. https://doi.org/10.1139/er-2013-0078

Pataki, D. E., McCarthy, H., Gillespie, T., Jenerette, G. D., \& Pincetl, S. (2013). A trait-based ecology of the Los Angeles urban forest. Ecosphere, 4(6), 1-20. https://doi.org/10.1890/ES13-00017.1

Pauleit, S., Jones, N., Garcia-Martin, G., Garcia-Valdecantos, J. L., Rivière, L. M., Vidal-Beaudet, L., Bodson, M., \& Randrup, T. B. (2002). Tree establishment practice in towns and cities-results from a European survey. Urban Forestry \& Urban Greening, 1(2), 83-96. https://doi.org/10.1078/1618-8667-00009

Pedersen, P., \& Brun, J. (2013). Landskapsplanter- utvalgsarbeid for norske grøntanlegg. Sluttrapport I. Registreringer i "Treforsøksparken" på UMB i Ås [Landscape plants - Plant selection for Norwegian green spaces. Assessment of "the tree research field" at University of Life Sciences at Ås]. Norwegian Udri.

Ramage, B. S., Roman, L. A., \& Dukes, J. S. (2013). Relationships between urban tree communities and the biomes in which they reside. Applied Vegetation Science, 16(1), 8-20. https://doi.org/10.1111/j.1654-109X. 2012.01205.x

Roman, L. A., Battles, J. J., \& McBride, J. R. (2014). Determinants of establishment survival for residential trees in Sacramento County, CA. Landscape and Urban Planning, 129, 22-31. https://doi.org/10.1016/j. landurbplan.2014.05.004

Roman, L. A., McPherson, E. G., Scharenbroch, B. C., \& Bartens, J. (2013). Identifying common practices and challenges for local urban tree monitoring programs across the United States. Arboriculture \& Urban Forestry, 39(6), 292-299.

Roman, L. A., van Doorn, N. S., McPherson, E. G., Scharenbroch, B. C., Henning, J. G., stberg, J. P., Mueller, L. S., Koeser, A. K., Mills, J. R., \& Hallett, R. A. (2020). Urban tree monitoring: A field guide. Gen. Tech. Rep. NRS-194. Madison, WI: US Department of Agriculture, Forest Service, Northern Research Station, 194, 1-48.

Sadeghabadi, R. M., Nouri, O., \& Deihimfard, R. (2020). Plant selection for semi-arid urban landscapes with an emphasis on climate change (case study: Tehran). Environmental Sciences, 18(1), 219-236.

Sæbø, A., Benedikz, T., \& Randrup, T. B. (2003). Selection of trees for urban forestry in the Nordic countries. Urban Forestry \& Urban Greening, 2(2), 101-114. https://doi.org/10.1078/1618-8667-00027

Sjöman, H., \& Slagstedt, J. (2015). Rätt träd på rätt plats. Träd I Urbana Landskap, 332-360.

Smith, I. A., Dearborn, V. K., \& Hutyra, L. R. (2019). Live fast, die young: Accelerated growth, mortality, and turnover in street trees. PLoS ONE, 14(5), e0215846. https://doi.org/10.1371/journal.pone.0215846

Staudhammer, C., Escobedo, F., Lawrence, A., Duryea, M., Smith, P., \& Merritt, M. (2011). Rapid assessment of change and hurricane impacts 
to Houston's urban forest structure. Arboriculture \& Urban Forestry 37(2), 60-66.

Steenberg, J. W., Millward, A. A., Nowak, D. J., \& Robinson, P. J. (2017). A conceptual framework of urban forest ecosystem vulnerability. Environmental Reviews, 25(1), 115-126. https://doi.org/10.1139/er-20160022

Sunday, J. M., Bates, A. E., Kearney, M. R., Colwell, R. K., Dulvy, N. K., Longino, J. T., \& Huey, R. B. (2014). Thermal-safety margins and the necessity of thermoregulatory behavior across latitude and elevation. Proceedings of the National Academy of Sciences, 111(15), 5610-5615. https://doi.org/10.1073/pnas.1316145111

Tavşanoğlu, Ç., \& Pausas, J. G. (2018). A functional trait database for Mediterranean basin plants. Scientific Data, 5(1), 1-18.

Trowbridge, P. J., \& Bassuk, N. L. (2004). Trees in the urban landscape: Site assessment, design, and installation. John Wiley \& Sons.

Tubby, K., \& Webber, J. (2010). Pests and diseases threatening urban trees under a changing climate. Forestry: An International Journal of Forest Research, 83(4), 451-459. https://doi.org/10.1093/forestry/cpq027

Tyler, G. (1996). Cover distributions of vascular plants in relation to soil chemistry and soil depth in a granite rock ecosystem. Vegetatio, 127(2), 215-223. https://doi.org/10.1007/BF00044642

UN. (2018). United Nations: The world's cities in 2018. Department of Economic and Social Affairs, Population Division, World Urbanization Prospects, 1-34.

Van der Veken, S., Hermy, M., Vellend, M., Knapen, A., \& Verheyen, K. (2008). Garden plants get a head start on climate change. Frontiers in Ecology and the Environment, 6(4), 212-216. https://doi.org/10.1890/ 070063

van Doorn, N. S., \& McPherson, E. G. (2018). Demographic trends in Claremont California's street tree population. Urban Forestry \& Urban Greening, 29, 200-211. https://doi.org/10.1016/j.ufug.2017.11.018

van Doorn, N. S., Roman, L. A., McPherson, E. G., Scharenbroch, B. C., Henning, J. G., Östberg, J. P., Mueller, L. S., Koeser, A. K., Mills, J. R., \& Hallet, R. A. (2020). Urban tree monitoring: A resource guide. Gen. Tech. Rep. PSW-GTR-266. Albany, CA: US Department of Agriculture, Forest Service, Pacific Southwest Research Station, 132, p. 266.

Venter, Z. S., Krog, N. H., \& Barton, D. N. (2020). Linking green infrastructure to urban heat and human health risk mitigation in Oslo, Norway.
Science of the Total Environment, 709, 136193. https://doi.org/10. 1016/j.scitotenv.2019.136193

Vogt, J., Gillner, S., Hofmann, M., Tharang, A., Dettmann, S. Gerstenberg, T., Schmidt, C., Gebauer, H., Van de Riet, K., \& Berger, U. (2017). Citree: A database supporting tree selection for urban areas in temperate climate. Landscape and Urban Planning, 157, 14-25. https:// doi.org/10.1016/j.landurbplan.2016.06.005

Walters, C. (1986). Adaptive management of renewable resources. McGraw Hill.

Yan, P., \& Yang, J. (2018). Performances of urban tree species under disturbances in 120 cities in China. Forests, 9(2), 50. https://doi.org/10. 3390/ 99020050

Yang, J. (2009). Assessing the impact of climate change on urban tree species selection: A case study in Philadelphia. Journal of Forestry, 107(7), 364-372.

Zscheischler, J., Westra, S., Hurk, B. J., Seneviratne, S. I., Ward, P. J., Pitman, A., AghaKouchak, A., Bresch, D. N., Leonard, M., \& Wahl, T. (2018). Future climate risk from compound events. Nature Climate Change, 8, 469-477. https://doi.org/10.1038/s41558-018-0156-3

\section{SUPPORTING INFORMATION}

Additional supporting information may be found in the online version of the article at the publisher's website.

How to cite this article: Esperon-Rodriguez, M., Rymer, P. D., Power, S. A., Barton, D. N., Cariñanos, P., Dobbs, C., Eleuterio, A. A., Escobedo, F. J., Hauer, R., Hermy, M., Jahani, A., Onyekwelu, J. C., Östberg, J., Pataki, D., Randrup, T. B., Rasmussen, T., Roman, L. A., Russo, A., Shackleton, C., ... Tjoelker, M. G. (2022). Assessing climate risk to support urban forests in a changing climate. Plants, People, Planet, 1-13. https://doi.org/10.1002/ppp3.10240 